\title{
De maio 68 a abril de 1969 imaginários de revoluções no cinema
}

\author{
José da Silva Ribeiro
}

Faculdade de Artes Visuais, Universidade Federal de Goiás, Brasil

CEMRI - Media e medições culturais, Universidade Aberta, Portugal

GECND - Grupo de Estudos de Cinema e Narrativas Digitais - AO NORTE, Portugal

\begin{abstract}
Fifty years ago, a movement in Paris unleashed a profound change in customs and left deep marks on society, despite its restraint by elections, changes in the university and factories. The 'events' of May 1968, because of their breadth, their role in young people and foreigners, the new forms of action and participation that gave rise to them, and certain qualitatively new aspects of the claims presented, not only revealed the political power of the labor movement (paralyzing power and blocking institutions), but they also constituted a "subversive" experience of incalculable theoretical and practical significance in the process of developing social struggles both in France and in other European countries. It also inaugurated a new stage which has come to mean a real "historical change": "trade union power" gave way to the "workers' power" that spread throughout Europe - France, Italy, Germany and Sweden itself. The echoes of May 1968 arrived in Portugal immediately, but it is mainly in April 1969 that in Coimbra there is a university crisis that can not fail to be referenced. These events also provoked changes in the cinema that occupied the rooms with dozens of films made in the years that followed and to this day the most recent film that resumes this movement is the film by João Moreira Salles No intenso agora (2017). In Portugal so far no film has plunged deeply into these events. Because? Why is it that after 50 years cinema resumes this theme? Why did Portuguese cinema forget the Coimbra crisis of 1969?
\end{abstract}

Keywords: May 1968 Paris, April 1969 Coimbra, Cinema, No Intenso Agora (2017), Le Drôle de Mai (2008)

\section{Introdução}

Há cinquenta anos desencadeou-se em Paris um movimento que transformou profundamente os costumes e deixou marcas profundas na sociedade, não obstante sua contenção pelas eleições, pelas mudanças na Universidade e nas fábricas. Os «acontecimentos» de Maio de 1968, pela sua amplitude, pelo papel que neles tiveram os jovens e os estrangeiros, pelas novas formas de ação e de participação a que deram origem e por certos aspetos qualitativamente novos das reivindicações apresentadas, não só revelaram a força política do movimento operário (paralisando o poder e bloqueando as instituições), mas constituíram também uma experiência «subversiva» de incalculável significado teórico e prático, no processo de desenvolvimento das lutas sociais, tanto em França como noutros países europeus. Inaugurou também uma nova etapa que veio a ter o significado duma verdadeira «mutação histórica»: o «poder sindical» deu lugar ao «poder operário» que se espalhou pela europa - França, Itália, Alemanha e na própria Suécia. Os ecos do maio de 1968 chegaram a Portugal de imediato, mas é sobretudo em abril de 1969 que em Coimbra estala uma crise universitária que não pode deixar de se referenciar. Estes acontecimentos provocaram também mudanças no cinema que ocupou as salas com dezenas de filmes realizados nos anos subsequentes e até aos dias de hoje o mais recentre filme que retoma este movimento é o filme de João Moreira Salles No intenso agora (2017). Em Portugal até ao presente nenhum filme mergulhou profundamente nestes acontecimentos. Porquê? Porque é que passados 50 anos o cinema retoma esta temática? Porque é que o cinema português esqueceu a crise de Coimbra de 1969?

\section{Maio de 68, cinema, movimento estudantil, liberdade de costumes, imaginação ao poder}

Tinha dezanove anos e frequentava o curso de filosofia da Universidade Católica Portuguesa quando se deu o maio de 1968. Os ecos chegavam a Portugal de múltiplas formas filtrados pela censura do regime, pelos textos policopiados das associações de estudantes ou dos partidos políticos clandestinos, pelas canções e pelos testemunhos de emigrantes portugueses que viviam nos arredores de Paris. Como afirma Pedro de Vasconcelos "também aqui fervilhava a contestação juvenil em tertúlias, conferências, manifestações de rua, greves, panfletos clandestinos, palavras de ondem pintadas nas paredes" (público 10 de maio de 2018). Para Eglantina Monteiro "Foram as relações de dominação tradicionais na Universidade, na Fábrica, entre o Homem e a Mulher que vacilaram. É a recusa da autoridade do Estado, dos partidos, dos sindicatos, dos professores.... O famoso slogan: Peace and Love, a criação de escolas e comunidades alternativas, liberdade sexual e independência das mulheres em relação ao poder masculino que a pílula indelevelmente suporta, o consumo de drogas como outro modo de percecionar o mundo, são alguns dos aspetos mais visíveis da mudança da sociedade tradicional, marcada pelo catolicismo doloroso ou pelo protestantismo puritano, para a cultura contemporânea" (Exposição Ano 68 e ainda, Galeria Mira). 


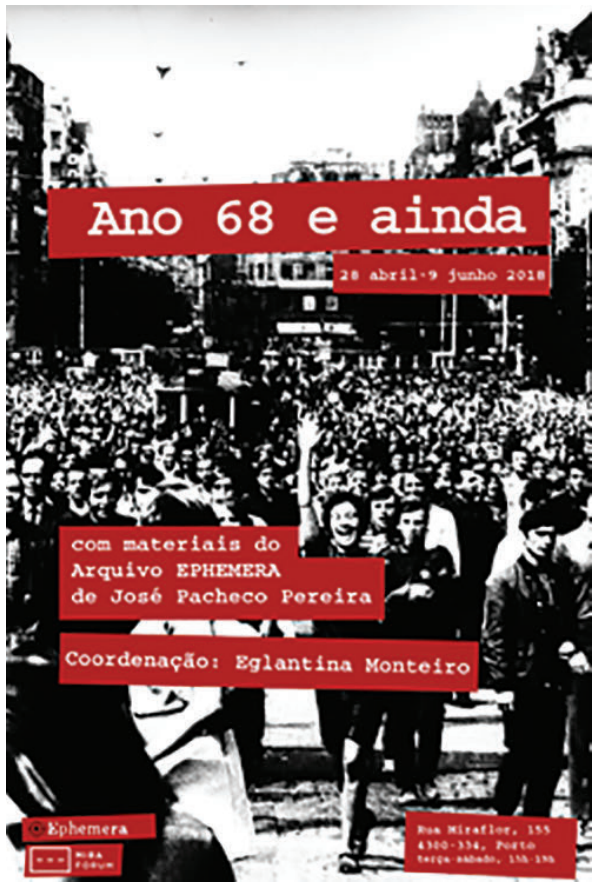

Figura 1 - Cartaz da exposição coordenada por Eglantina Monteiro, no Mira Fórum, com materiais do arquivo EPHEMERA de José Pacheco Pereira

No ano seguinte, em 17 abril de 1969, na inauguração do edifício das matemáticas da Universidade de Coimbra pelo Presidente da República, o presidente da Associação Académica de Coimbra levantou-se e pediu para falar na cerimónia. A resposta foi evasiva e, terminada a sessão, o Presidente da República, Ministro da Educação, Ministro das Obras Públicas, Reitor da Universidade e demais componentes da mesa saíram precipitadamente da sala. Foi a vez dos estudantes falarem. As imagens da época são sobretudo as imagens oficiais - fotografias $^{1}$ e a reportagem da Radio Televisão Portuguesa. As fotos são distantes algumas, outras aproximam-se e entram nos acontecimentos, nas lutas estudantis pela solidariedade dos fotógrafos de Coimbra e pela ação da secção de fotografia da AAC que monta uma exposição itinerante como forma de contestação da informação divulgada pelos media controlados pelo regime. Crê-se no testemunho da imagem..

Crê-se pela realidade indesmentível e incontestável das imagens, "aqui se expõe mais a VERDADE em desafio às 'pseudonotícias descuidadas, ao concerto orquestrado dos editoriais de província e à planificada e organizada pedagogia propagandística. Na escalada irreversível por uma UNIVERSIDADE NOVA e em homenagem ao grande passo em frente dos estudantes na conquista dos seus direitos chamamos a este trabalho - Exposição 17 de Abril." (Documento com que a Direção da Secção Fotográfica anunciava a Exposição 17 de Abril).

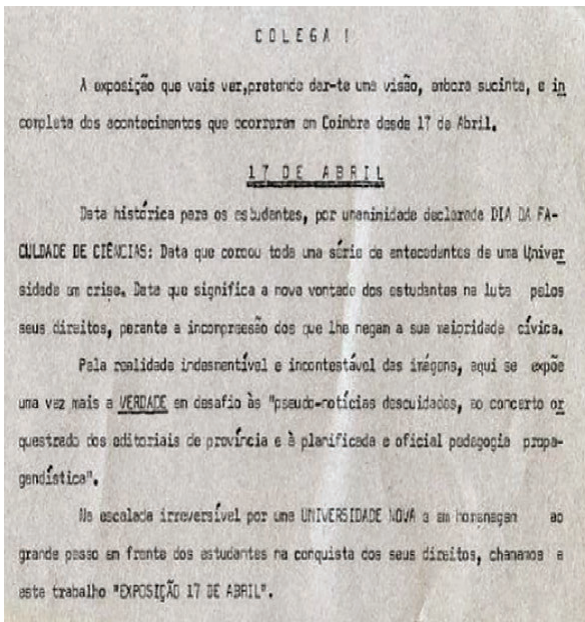

Figura 2 - Fac-simile do panfleto

As fotografias não deixavam de mostrar a situação política em Portugal e as reivindicações dos estudantes em finais dos anos de 1960 - a forte presença militar num evento académico (a Universidade era uma dos grandes redutos de oposição à ditadura do Estado Novo), a população que participa no evento, as reivindicações estudantis "democratização do ensino", "exigimos diálogo", "estudantes no governo da universidade" "reintegração dos professores e alunos expulsos", a situação escolar "em Portugal $40 \%$ de analfabetos" e a unidade dos estudantes "Ciências apoia a sua junta de delegados", "não esquecemos os 9 pontos". Os nove pontos eram "as reivindicações básicas do movimento estudantil português: 1. Imediata demissão da Comissão Administrativa e eleições para a AAC. 2. Legalização de todas as Comissões Pró-associações e criação de condições para a existência de Associações de Estudantes onde ainda não as houver. 3. Participação de estudantes democraticamente eleitos na gestão dos serviços criados pelo Governo respeitantes às necessidades estudantis. 4. Participação de estudantes democraticamente eleitos no governo da Universidade. 5. Intervenção das Associações de Estudantes, na qualidade de únicos representantes dos estudantes em todas as questões e instâncias em que se decida da vida e da Reforma da Universidade e do Ensino em geral. 6. Amnistia de todos os estudantes expulsos e presos, reintegração na universidade de todos os professores expulsos e abolição de todas as medidas discriminatórias não pedagógicas ou científicas no recrutamento de professores. 7 . Revogação de toda a legislação circum-escolar e anti associativa, 8. Legalização dos órgãos federativos e lançamento das bases de uma União Nacional dos Estudantes Portugueses, 9. Direito a livre informação por parte dos estudantes no que diz respeito à problemática e 
ao processo de sua atuação e posição" (NAMORADO, 1989 Anexo 8 p. 112 e 113)

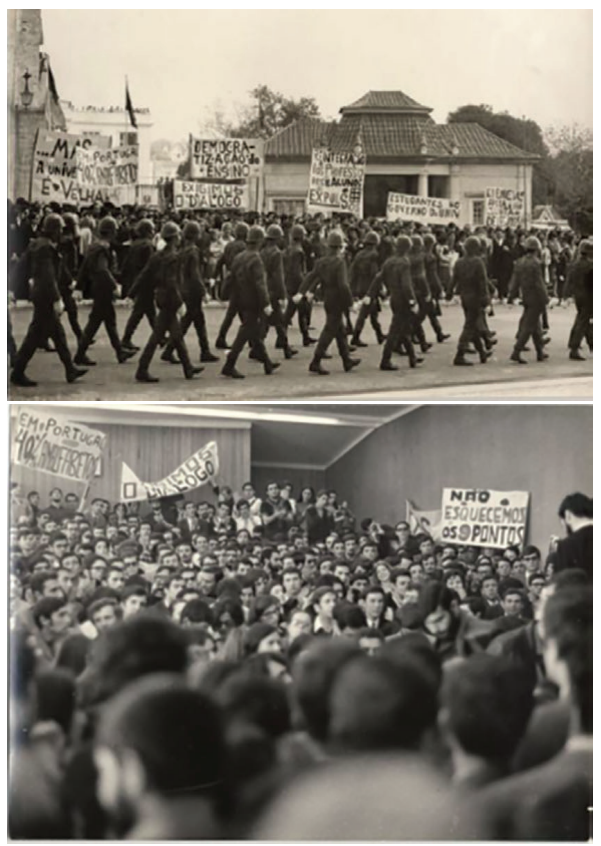

Figura 3 - Fotografias de 17 de abril: desfile militar e Assembleia na FaC Ciências

No dia seguinte, com voz autoritária, o Ministro da Educação falavas na RTP

"quando o senhor Presidente e demais autoridades saíram da sala verificaram-se mais uma vez manifestações de grave desrespeito, sendo necessário abrir caminho perante uma massa de três centenas de estudantes que se tinham aglomerado e, em coro, bradavam protestos e expressões incompatíveis com o respeito devido à presença naquele lugar do supremo magistrado da nação". ${ }^{2}$ (arquivo RTP).

Seguiu-se uma crise académica que deu origem múltiplas formas criativas de resistência e contestação ao regime por parte dos estudantes - de criação e aprofundamento da relação com a população da cidade de Coimbra com a distribuição de flores ${ }^{3}$, organização de espetáculos - teatro e música ${ }^{4}$; decretado luto académico e greve aos exames; de resistência em relação às intervenções da polícia que ocupa a cidade de Coimbra; de transformação em grande comício no Estádio do Jamor na final da Taça de Portugal ${ }^{5}$ em que a equipa de Futebol da Associação Académica de Coimbra $^{6}$ se confrontava com o Benfica. De muitos destes acontecimentos não existem imagens. Estas poderiam constituir, se tornadas públicas ou se apreendidas pela PIDE - Polícia Internacional e de Defesa do Estado, uma forma de testemunhar a presença e as estudantis e consequente prisão.

Portugal vivia um período muito complexo. $\mathrm{Na}$ década de 1960 dá-se uma emigração massiva, na maior parte clandestina, para o centro da Europa ${ }^{7}$ e inicia-se a guerra colonial com três frentes guerra Angola, Moçambique e Guiné. Era também o princípio do fim de Salazar - Presidente do Conselho, que, a 03 de agosto de 1968, cai da cadeira, no terraço do Forte de Santo António, no Estoril, quando o calista Augusto Hilário se preparava para lhe tratar dos pés sendo substituído por Marcelo Caetano setembro de 1968.

Como consequência desta contestação e de dias que abalaram o regime foram incorporados no serviço militar 49 estudantes que, mais tarde, se entendeu ser um dos maiores erros políticos do regime - a contestação académica, as canções de lutas passaram para dentro dos quartéis em Portugal e nas colónias. Rui Pato, músico e estudante de medicina, que acompanhara José Afonso ${ }^{8}$ e António Correia de Oliveira ${ }^{9}$, refere que as canções passaram a ser cantadas também pelos militares. Refere ainda que na caserna tinham cartazes com o poema de Reinaldo Edgar de Azevedo e Silva Ferreira - Receita para fazer um herói:

Tome-se um homem,

Feito de nada, como nós,

E em tamanho natural.

Embeba-se-lhe a carne,

Lentamente,

Duma certeza aguda, irracional,

Intensa como o ódio ou como a fome.

Depois, perto do fim,

Agite-se um pendão

E toque-se um clarim.

Serve-se morto.

Dois anos depois em setembro de 1971 fui incorporado no serviço militar. Aí as vozes que se pronunciavam sobre a guerra colonial, a democratização do país, eram tão claras quanto as que me envolvia na Universidade. O que acontecia no então Instituto Superior de Economia onde frequentava o curso de Organização e Gestão de Empresas completava-se com a informação a que tinha acesso no Comando da Região Aérea em Monsanto onde cumpria o serviço militar obrigatório.

Até ao momento não encontrei um documentário que abordasse este tema, que recuperasse o rico espólio de imagens, sobretudo fotográficas, as vozes dos participantes nos acontecimentos, as canções que documentavam as lutas e uma reflexão sobre as imagens dos acontecimentos do final dos anos de 1969. A televisão apropriou-se dessas imagens e dos testemunhos mais mediáticos para as comemorações de 30 e 40 anos pós 1969. Continuo procurando documentários que documentem esta época. Talvez 50 anos depois de abril de 1969 o cinema procure fragmentos deixados no tempo e os reconfigure no presente do país.

Mais tarde meu interesse pelas migrações e pela antropologia visual como investigador do Centro de Estudos das Migrações e das Relações Interculturais, cujo Laboratório de Antropologia Visual coordenava, levou-me, em colaboração com prestigiados 
investigadores em Migrações, a criação de uma base de dados de filmes ${ }^{10}$ que abordavam a migração portuguesa. Também pude contatar com cineastas que realizaram em França filmes sobre a imigração portuguesa. Conheci entre outros documentaristas José Vieira que deu particular atenção a como emigrantes portugueses viveram o maio de 68 no filme Le Drôle Mai Chronique des années de boue / O engano de maio: Crónica dos anos da lama (2008).

José Vieira, migrou em 1965, com 7 anos de idade para França. Viveu os primeiros anos de estada em Paris no Bidonville de Massy - um lugar liminar onde se descobria as diversas regiões de origem dos imigrantes, se vivia na miséria e convivia com liberdade, se descobriam novas realidades e oportunidades de trabalho. Com 16 anos confronta-se com as mudanças políticas em Portugal (revolução de abril) através das canções de Luís Cília ${ }^{11}$ e José Mário Branco $^{12}$ que conhecera e mais tarde viriam a estar presentes nos seus filmes. Desde muito cedo tornouse militante nos movimentos cívicos dos emigrantes, no FASTI - movimento de solidariedade com as pessoas imigradas e nascidas nos anos sessenta nos bidonvilles da região parisiense, no CEDEP - Coletivo de Estudos e Dinamização da Emigração Portuguesa onde se torna responsável pelo audiovisual, participa na marcha para a igualdade do movimento Convergence 84, no Mouvement Beur.

Estes foram os fatores que levaram José Vieira a fazer filmes sobre a imigração portuguesa em França. O catolicismo e o salazarismo enraizado na escola que frequentou em Portugal durante pouco tempo e nos migrantes que habitavam os bidonville, o estigma de ter de ocultar suas vivências perante os colegas de escola em França e seus amigos em Portugal. As esperanças que abril de 1974 abriu, Vieira viveu-as fora da comunidade dos imigrantes portugueses em França pelas canções e mais tarde pela participação movimentos de solidariedade com os emigrantes em que participou. Estes fatores marcam profundamente sua obra.

Em 2008 José Vieira realizou o filme Le Drôle Mai Chronique des années de boue / O engano de maio: Crónica dos anos da lama em que focaliza três realidades e dois tempos diferenciados: os acontecimentos de maio de 68 em Paris e a vida dos imigrantes portugueses nos bidonville nos arredores da cidade em imagens de arquivo e a vozes dos migrantes portugueses que viveram esses acontecimentos quarenta nos depois. Trata-se, pois, uma narrativa multissituada no tempo e no espaço. As vozes silenciadas em maio de 68 pelo governo francês, pela omnipresença da polícia política portuguesa (PIDE/ DGS) e pela dificuldade de compreensão e recusa de participação nos complexos e inesperados fenómenos que estavam a acontecer ganham um papel importante na interpretação da experiência vivida dos anos da lama (Chronique des années de boue). O filme gira em torno da narrativa de um homem, José Vieira, em busca da história de imigrantes portugueses apanhados nos acontecimentos do maio de 68. Nos primeiros dias de bom tempo o bidonville tornava-se uma aldeia portuguesa. Quando a primavera chegava, a lama começava a secar. No domingo, havia bailes, as famílias encontravam-se. Pairava no ar o cheiro de nostalgia ainda fresca. Mas na Primavera 68, em meados de maio, o ar de repente tornou-se insuportável. A atmosfera envenenada de rumores e medos mais irracionais. Os imigrantes portugueses tinham vindo para a França para escapar à pobreza. Dedicavam todas as suas forças na procura de uma vida melhor. A revolta de maio constituía uma complexa situação que colocava em risco todos os seus propósitos - 0 do trabalho e de angariar um pecúlio que os tirasse da miséria de onde partiram, mas também a ameaça de serem extraditados de França e de terem de regressar a Portugal de onde, um grande número tinha saído clandestinamente (a salto). Os acontecimentos geraram, pois, junto dos portugueses o medo de serem mandado de volta à miséria que haviam deixado numa situação económica e política particularmente difícil e pior que a da situação de partida. Maio de 68 foi para eles um período de desordem, revolta e perigo. Dificilmente compreendiam a revolta estudantil e suas palavras mobilizadoras e, sua participação nos sindicatos era reduzida quer pela posição dos sindicatos franceses em relação à imigração quer porque uma grande parte dos migrantes portugueses eram, em Portugal, agricultores, do interior e norte do país, sem qualquer contato com movimentos operários, ou com o exterior (muitos dos migrantes tinham apenas saído de suas terras para cumprirem o serviço militar ou mais raramente para ocuparem os lugares de marçanos nas cidades mais próximas), católicos e conservadores, profundamente marcados pela ideologia do regime do Estado Novo (Salazarismo). Em plena greve geral, dezenas de moradores dos bidonvilles, apenas alguns dos que estavam legalmente, regressaram de emergência a Portugal. Aquando dos acontecimentos do maio de 1968, a imigração portuguesa estava a começar a estabelecerse em França - Entre 1958 e 1974, cerca de um milhão de portugueses instalam-se em França, dispostos a trabalharem em tudo o que Ihes apareça. A maior onda de imigração que França conheceu começou em 1963. Em 1968, havia 300.000 portugueses em França. Maio de 68 vai surpreendê-los e por em causa seus desígnios de regresso para construírem a casa no país de origem. Estavam num beco sem saída, de mãos e pés atados, em todas as suas saídas possíveis. Os acontecimentos do maio de 68 foi um choque para os portugueses recém-chegados. De origem camponesa, e, muitas vezes analfabetos, nasceram e cresceram sob a opressão de Salazar. Em Portugal, a greve era considerada um crime, a acusação e a delação era um sistema instituído como causa nacional, a guerra colonial constituía não só um sorvedouro das remessas dos emigrantes, mas uma ameaça para os mais jovens que saiam do país antes de cumprirem o serviço militar obrigatório, considerados refratários. Este migrantes moviam-se em dicotomia "nós e os comunistas" como se expressam no filme. Esta imigração foi vigiada e frequentemente confundida com um movimento de emancipação. Muitos entraram em pânico com 
a ideia de que uma guerra civil poderia eclodir e os comunistas tomar o poder, milhares de portugueses fizeram as malas para voltar a Portugal. Por outro lado, para os adversários de Salazar, que viviam na França como imigrantes ou como exilados, maio de 68 constituía uma grande oportunidade da sua luta contra a ditadura e para o despertar de seus compatriotas para a democracia.

Le Drôle de mai (2008) é, segundo Vieira, uma terceira etapa na sua obra que conta os anos que se seguem a 1968, instalação progressiva na sociedade francesa decorrentes das mudanças verificadas em França com o maio de 68 e em Portugal com a Revolução dos Cravos em 1974. Os portugueses ainda que aparentemente bem integrados, e muitos, realmente bem integrados, sentem-se, por vezes, considerados como gente sem história e sem voz. O filme restitui-lhes a voz e a história dos anos da lama. Retira-os desse tempo e projeta-os num país que, na altura de realização do filme ainda tinha voz e onde se teciam solidariedades com os migrantes que do Brasil, África ou dos países do Leste se instalavam em Portugal como imigrantes. O trabalho do realizador só se tornou possível por partilhar com eles a história e o percurso migratório porque "se exprimem pouco, de maneira surda, o que torna difícil fazer filmes com eles" (Vieira, 2010).

Quando me propus iniciar esta reflexão sobre o meio século que decorreu sobre o maio de 68 vieramme logo à memória filmes realizados por cineastas presentes nos acontecimentos Cris Marker, Jean-Luc Godard, os que estão disseminados nas páginas web ${ }^{13}$ ou a obras coletivas como Longe do Vietnam (1967) de Joris Ivens, William Klein, Claude Lelouch, Agnès Varda, Jean-Luc Godard, Chris Marker, Alain Resnais. Também me chamaram a atenção os filmes Tous au Larzac (2011), Les LIP, l'imagination au pouvoir (2007) de Christian Rouaud realizado a partir de imagens de arquivo de imagens amadoras, de imagens de televisão e dos testemunhos atuais dos participantes nos acontecimentos: resistência dos camponeses de Larzac e dos operários da LIP ${ }^{14}$.

Agora no Brasil são as lições de João Moreira Sales, documentarista brasileiro, diretor da revista PIAUÍ e criador com o irmão Walther Salles da produtora Videofilmes (1987) e Presidente do Instituto Moreira Salles $^{15}$ que me aguçaram o olhar. Antes Santiago (2007) tinha já desertado minha atenção à narrativa na primeira pessoa, realizada pelo irmão e por uma certa estética do fracasso - "ensaio" fílmico sobre como fazer (ou não fazer) um documentário" (LINS, 2015) que o narrador refere no filme e que o diretor relembra com frequência. Na verdade, o filme rodado em 1992 e retomado 13 anos depois em 2005 questiona de forma reflexiva o modo das primeiras filmagens e a primeira ideia de montagem... questiona-as com a narração na primeira pessoa assumida pelo irmão (01:53 a 03:48).

João Moreira Sales, em No intenso agora (2017), filme realizado apenas com imagens procedentes de arquivos diversos, sobretudo os rolos que encontrara em casa da família registados por sua mãe durante a viagem que fizera à China com um grupo de empresários e artistas. A narração do próprio João Moreira Salles leva-nos a uma leitura minuciosa das imagens e da sua construção - olhar da câmara no maio de 68, na Primavera de Praga, imagens de família, utilização política da morte. Como no filme de José Vieira o maio de 68 e as imagens de família estão presentes no decorrer de todo o filme. A família Moreira Salles também estava em Paris, não como imigrante, mas numa situação decorrente da deposição de João Belchior Marques Goulart (Jango), Presidente do Brasil entre 1961 e 1964, deposto pelo Golpe Militar de 1964, da lealdade com o Presidente e das pressões do regime militar para depor contra Jango, de que Walther Moreira Salles, pai do cineasta, foi ministro da Fazenda. Os acontecimentos de maio de 68 vão levar a família a regressar ao Brasil.

O filme aborda sobretudo a felicidade, o modo e as razões de as pessoas se sentirem felizes nas mais diversas situações, mas sobretudo a felicidade de sua mãe nas imagens de família e na visita à China. Pessoas felizes na Checoslováquia talvez numa primavera, famílias felizes nas imagens dos primeiros passos de uma bebé, mas também imagens que excluem quem não pertence a essa felicidade ${ }^{16}$, felicidade transbordante da mãe na visita à china, felicidades dos estudantes confrontando-se com a brutalidade do aparelho policial no maio de $68 \mathrm{em}$ França. Felicidade sempre efémera: o maio de 68 termina com o reforço do poder de De Gaulle, as imagens de felicidade na Checoslováquia terminam com a invasão de Praga pelos tranques soviéticos e com a imolação do jovem Jan Palach, manifestações de 68 no Brasil e a morte. Também deixou de ser feliz. Aí o cinema vai filmar a utilização dos heróis mortos no esmorecer da intensa felicidade, do intenso agora, vivida pelas pessoas no decorrer dos acontecimentos e do controle destes pelos poderes instituídos.

O filme ganha particular intensidade ao apresentar uma personagem - mãe do realizador nos contextos de múltiplos acontecimento no Brasil, em França, na europa, na Checoslováquia, na China e de uma onda de mudanças políticas, culturais e sociais em que muitas delas terminam em tragédia ou em indiferença ${ }^{17}$ como a que leva Jan Palach ao desespero e ao suicídio. Ver intenso agora "repudio à acomodação que estava a tomar conta do país" (01:31:32 - 01:33:30). O filme é também premonitório do que se passa atualmente no Brasil e no mundo (Como as democracias morrem, 2018 de Steven Levitsky e Daniel Ziblatt).

Vivi tempos semelhantes em Portugal desde 1969, mas sobretudo depois de abril de 1974. Era a revolução dos cravos. Que a poetisa Sophia de Mello Breyner Andresen descreve assim a passagem da felicidade à deceção, da liminaridade a situações instituídas, as mesmas que o personagem chinês da obra da Peterson teima em ver na escrita de Mao. Não um discurso político, mas o poema que começa assim "como um vago sonho relembrado / penso em minha aldeia de então / eu amaldiçou-o o rio do tempo". Para Sophia era assim o tempo de passagem, talvez como a crença dos jovens no maio de 1968 ou os chineses (e mãe de João Moreira Sales na Revolução cultural. 
25 de Abril

Esta é a madrugada que eu esperava

O dia inicial inteiro e limpo

Onde emergimos da noite e do silêncio

E livres habitamos a substância do tempo

(Sophia de Mello Breyner Andresen, 1977, p. 28)

Será Possível

Será Possível que nada se cumprisse?

Que o roseiral a brisa as folhas de hera

Fossem como palavras sem sentido

- Que nada sejam senão seu rosto ido

Sem regresso nem resposta - só perdido?

(Sophia de Mello Breyner Andresen, 1977, p. 61)

Apesar das Ruínas

Apesar das ruínas e da morte,

Onde sempre acabou cada ilusão,

A força dos meus sonhos é tão forte,

Que de tudo renasce a exaltação

E nunca as minhas mãos ficam vazias.

(Sophia de Mello Breyner Andresen, Antologia Poética)

Em No Intenso agora João moreira Sales diz.:

... compreendo que mamãe estabelece uma hierarquia entre o surpreendente (a China da Revolução Cultural) e o previsível (Japão) considerando superior o que surpreende. Ela resumiu assim essa preferência: "ao choque do encontro inesperado sucede a inefável noção da forma inusitada" Esta frase descreve o encontro dela com a China. Lá ela se viu diante não só de flores pontes e lagos de tirar o seu folego, mas também de homens e mulheres cuja experiência de vida era radicalmente diferente da dela. Ela conversou com operários, camponeses, estudantes de medicina, ideólogos do partido, ferroviários... Tudo era novo, tudo aguçava a sua curiosidade, tornava viva a consciência de estar lá, naquele momento da história. Relatou a experiência com emoção, a inefável emoção que sucede ao choque do encontro inesperado. Alguma coisa nova brotava comovente e vital....

Aqui está ela no Japão. Não sei se antes, se depois da viagem à china... Julgou tudo um pouco mais previsível e escreveu: "a planificação japonesa é obviamente cerebral a chinesa pode lograr o observador incauto muito mais profunda e de sentido quase filosófico conserva a aparência de casualidade"

O filme é uma carta de amor à mãe nas imagens e nos diversos estádios de sua vida. As imagens

"ao longo dos anos 60 minha mãe aparece em vários filmes caseiros... são viagens de férias, cenas do quotidiano, aniversário de família... Ela parece feliz, com gosto de estar viva. A partir dos anos 70 as imagens começam a rarear e de $80 \mathrm{em}$ diante quase nada... olhando para o conjunto volto sempre ao material da China são imagens pobres e mal filmadas, no entanto, elas registam o encontro de minha mãe com a realidade de um país oposto a tudo o que ela conhecia. Na minha memória nada deixava minha mãe tão acesa quanto a lembrança daque le tempo. Era com gosto que falava, com alegria, com uma intensidade que o tempo the viria roubar. Ela foi feliz na China e por isso gosto de pensar nela lá, quando tudo parecia possível... O centro do que minha mãe considerou bonito estava a ideia do inesperado. Bonito seria surpresa, aquilo que não pode ser antecipado (No Intenso agora. 01: 55:54 - 01:59:46)

Imagens da China: manifestações, escultura de um elefante gigante outras esculturas gigantes visitadas por turistas (talvez os turistas franceses que acompanhavam a mãe), grande prédio japonês, a mãe com um dicionário dá os marcadores a um animal, templos japoneses de volta as imagens da China.

A vida passa a correr... O jovem Mao escreve e não se sabe o quê. No romance do Norueguês Per Peterson o personagem principal, um militante maoista já perto da meia idade, especula sobre a fotografia de Mao que tinha no quarto quando era estudante e jovem. Ele conta: "a imagem de Mao era a famosa fotografia retocada, no qual está inclinado sobre a mesa, escrevendo com um desses pincéis chineses e sempre pensei torcendo por estar certo que o que escrevia não era uma daqueles artigos políticos ou filosóficos, mas um dos poemas dele talvez o que começa assim: "como um vago sonho relembrado / penso em minha aldeia de então / eu amaldiçoo-o o rio do tempo". 32 anos se passaram e a personagem continua eu torcia para que fosse esse poema porque mostrava um Mao humano, uma pessoa que me atraía, alguém que sentia como o tempo luta contra o corpo, uma sensação que era minha também. Como, sem aviso, o tempo era capaz de me alcançar e correr debaixo de minha pele como nos choques elétricos que não conseguia evitar por mais que tentasse... e quando finalmente cessavam e tudo serenava eu já era uma pessoa diferente daquilo que tinha sido e às vezes isso me desesperava"

JMS numa entrevista dada em Lisboa aquando do Doc Lisboa 2014 "o filma nasce do fado (Não Quero Rosas Vermelhas), diz Moreira Salles ${ }^{18}$, mas é pelos movimentos revolucionários que se afirma. Maio de 68, é claro, os traumáticos pós Primavera de Praga, naturalmente, a agitação estudantil no Brasil, a culminar até nos ecos no movimento de massas Brasil de 2013. No fundo, é o que se passa também agora".

A forma como a felicidade se vai exaurindo atravessa o filme remete-nos para muitas situações: a história da mãe (história da família), para a morte de Eduardo Coutinho a quem dedica o filme, para as revoluções falhadas, para a morte ou esquecimento dos heróis (ou protagonistas das revoluções, da resistência ou da luta), para a indiferença perante as tragédias. Como no poema de Mao "eu amaldiçoo o rio do tempo" ou "No Intenso Agora". No cinema... da saída da fábrica ao intenso agora. 
Não quero rosas vermelhas

A minha vida a correr

Como a chuva cai das telhas

A minha vida a correr

Como a chuva cai das telhas

Sou nova para morrer

Levar rosas vermelhas

Sou nova para morrer

E levar, e levar rosas vermelhas

Não quero rosas vermelhas

Antes cravos de outra cor

As rosas chamam abelhas

Os cravos chamam amores

Ter talento é ter centelha

Ter perfume é ter amores /odores

Não quero a rosa vermelha

Quero só o teu amor

Quero só, quero sempre o teu amor

Cravos chamam amores

As rosas chamam saudades

Ter coração é pior

Sempre a chamar a verdade

A minha vida a correr

Como a chuva cai das telhas

Sou nova para morrer

E Levar, e levar rosas vermelhas

Júlio Alberto Lopes

\section{Notas Finais}

${ }^{1}$ Os fotógrafos de Coimbra e secção de fotografia da AAC - Associação Académica de Coimbra produziram um completo registo fotográfico dos acontecimentos que em 1999 deram origem à publicação da Câmara Municipal da obra e José Veloso e João Gonçalves (JOCA) organizou esta coletânea legendada www1.ci.uc.pt/cd25a/media/ppt/Crise Acad-versao reduzida. pps com fotos, na sua maioria, "espólio da "Exposição 17 de Abril", que circulava ao tempo pelo País em mais uma iniciativa da Secção Fotográfica, e que foi entregue por Carlos Valente, em 1969, à Biblioteca Geral da Universidade de Coimbra, que a preservou até hoje".

${ }^{2}$ https://www.youtube.com/watch?v=Wz1PzZp2gUE.Acesso em abril de 2018.

${ }^{3}$ Flores de Coimbra de António Bernardino - https://www. youtube.com/watch?v=q1LEZvS-g_s. e https://www.youtube. com/watch?v=5zXdLIJYtcc. Acesso em janeiro de 2019.

${ }^{4} \mathrm{~A}$ música na Coimbra dos estudantes teve sempre um papel identitário muito forte, por vezes explorado pelo regime (Capas negras de Armando Miranda, 1947- https://www.youtube.com/ watch?v=tinYVGzsuzs e Rasganço de Raquel Freire, 2001), mas também um papel de contestação. Destes se destacam José Afonso e António Correia de Oliveira entre outros. Correia de Oliveira refere estes acontecimentos e a visita do Presidente da República em Se vossa excelência... https://www.youtube. com/watch?v=AVWT8eOW3ec Acesso em janeiro de 2019.

${ }^{5}$ Final da Taça de Portugal de 1960 - https://www.youtube. com/watch?v=p-zuE3x6p9Q e https://www.youtube.com/ watch?v=ibekH5YtR50. Acesso em abril de 2018.

${ }^{6}$ Secção de Futebol da Associação Académica de Coimbra (AAC), a associação de estudantes da Universidade de Coimbra. Chama-se ainda "equipa dos estudantes", uma vez que até à década de 70 a grande maioria dos jogadores eram estudantes universitários. A equipa de futebol da AAC tinha um grande poder de mobilização dos estudantes que a acompanhavam nas suas deslocações. Teve em 1969 papel preponderante na divulgação no espaço público das lutas estudantis. Acerca do papel da AAC nas lutas estudantis ver o filme Futebol de causas de António Ferreira e Tathiani Sacilotto (2009) https://youtu.be/ by6AqacVw9l. Acesso em janeiro de 2019.

${ }^{7} \mathrm{O}$ salto de Christian de Chalonge, 1967

${ }^{8}$ São de 1963 as canções com carater marcadamente político Os Vampiros e Menino do Bairro Negro. Participa no I Encontro da Chanson Portugaise de Combat, em Paris, em 1969.

${ }^{9}$ É também de 1963 Trova do Vento que Passa, um poema de Manuel Alegre, musicado por António Portugal e em 1969 Se vossa excelência... Estas e as canções referida de José Afonso tornaram-se símbolos de resistência antissalazarista da época. Em 1968 edita o álbum O Canto e as Armas também de Manuel Alegre.

${ }^{10}$ Base de dados ACIDI - Imagens e sonoridades das migrações. https://www.om.acm.gov.pt/documents/58428/ 183128/Caderno_OI3_.pdf/15c16724-e72d-461e-be2a$71 \mathrm{fe} 1176 \mathrm{fa} 7 \mathrm{f}$.

${ }^{11}$ Luís Cília fez a banda sonora do filme Salto e Laurete e les autres e as canções. Meu país, O menino negro não entrou na roda (1962). 1965: Portugal Resiste (Ep, Cercle du Disque Socialiste), 1967: La Poésie Portugaise de nos jours et de toujours 1 (Moshé Naim), 1967: O Salto (Single, UAF), 1969.

12 José Mário Branco: Seis cantigas de Amigo (EP, Arquivos Sonoros Portugueses, 1967) EP, Ronda do Soldadinho (Single, Ed. Autor, 1969) Single.

13 Como em CINEPLOT - http://cineplot.com.br/index. php/2016/10/20/15-filmes-sobre-maio-de-68/. Acesso em janeiro de 2019.

${ }^{14}$ LIP - Société Anonyme d'Horlogerie Lipmann Frères foi fundada em 1893, em Besançon, maior centro relojoeiro da França, foi pioneira na manufatura industrial de relógios em território francês e também no desenvolvimento dos relógios elétricos, eletrônicos e quartzo em nível mundial. Foi ocupada pelos trabalhadores em maio de 68 e em 1973 foi descoberto, por acaso, um plano secreto do conselho diretor para a demissão em massa de centenas de operários e corte de departamentos, o que revoltou os trabalhadores. A partir dai houve uma aturada resistência descrita no filme.

15 Instituto Moreira Salles é uma organização sem fins lucrativos fundada pelo diplomata e banqueiro Walther Moreira Salles em 1992, gerida pela família Moreira Salles com sede em Poços de Caldas (MG) de onde a família é originária, no Rio de Janeiro e em S. Paulo. É administrado pela família Moreira Salles e tem por finalidade exclusiva a promoção, a formação de acervos e o desenvolvimento de programas culturais nas áreas de fotografia, literatura, iconografia, artes plásticas, música e cinema.

${ }^{16}$ As imagens de família dos primeiros passos do bebé evocam os filmes Lumières em que pessoas pro acaso são apanhadas no enquadramento do cinematógrafo revelando o seu olhar de espanto perante as filmagens ou saindo de cena.

${ }^{17}$ Em Carta Capital Mino Carta refere também a indiferença no Brasil em 2018 perante a situação instalação de um governo autoritário e de um Estado totalitário, composto por militares, evangélicos, partidos de extrema direita aconselhado pelo guru Olavo de Carvalho - "o que mais me espanta é o silêncio das pessoas, a indiferença, a insensibilidade prova de uma ignorância crassa, profunda, inarredável..." https://www. youtube.com/watch?v=KpwD-9E70EA. Acesso em abril de 2019.

18 "Eu ouvi esse fado há quinze anos atrás e ficou-me na cabeça. É preciso fazer um filme que tenha esse fado Não Quero Rosas Vermelhas, da Maria Alice. E com a música do Rodrigo Leão porque eu sempre gostei muito do Madredeus, sempre gostei muito dele e tem um CD que se chama Cinema, que é uma maravilha, decidi procurá-lo, ele foi muito gentil e o filme ganhou o prémio de melhor trilha sonora no Festival de Cinema do Real, onde ganhou o melhor documentário SECAM, a trilha sonora e o prémio das bibliotecas. Mas a trilha sonora me deixou muito feliz. E eu vou passar no DocLisboa. Vai ser a primeira vez que vou mostrar lá e vou ficar muito feliz" - https:// www.insider.pt/2017/10/24/3930/ 